\title{
ANALISTAS DE DISCURSO E SUA PRÁTICA TEÓRICA E METODOLÓGICA
}

\author{
(Discourse analysts and their methodological \\ and theoretical practice)
}

Juliana de Freitas Dias ${ }^{1}$

\begin{abstract}
During the conventionally called late modernity, a series of social and material transformations have been emerging, which has led to a growing awareness of the importance of language that, in this context, inserts itself as the mediation system of all discourses. Given this potential of language to mediate our action on the world, to build social positions, to create beliefs and ideologies, the need and importance of analyzing the various social practices from the perspective of discourse becomes, therefore, very useful. I present in this article a theoretical and methodological reflection of Critical Discourse Analysis in order to propose a recontextualization of the CDA analytical framework, formulated by Choulariaki and Fairclough (1999).
\end{abstract}

Keywords: discourse, power, analytical framework, birth, identity.

\section{RESUMO}

No período que se convencionou chamar de modernidade tardia, uma série de transformações sociais e materiais têm ganhado forma, o que tem acarretado uma crescente conscientização sobre a importância da linguagem que, nesse contexto, se insere como o sistema mediador de todos os discursos. Em função dessa potencialidade da linguagem de mediar nossa ação sobre o mundo, de' construir posições sociais, de criar crenças e ideologias, a necessidade e a relevância de analisar as diversas práticas sociais sob a perspectiva do discurso torna-se, portanto, muito útil. Apresento neste artigo uma reflexão de cunho teórico e metodológico no bojo da Análise de Discurso Crítica

1.Professora e pesquisadora da Universidade de Brasília Depto. de Linguística, Português e Línguas Clássicas (UnB/LIP). Mestre e Doutora em Linguística pela Universidade de Brasília. Analista do discurso, linha inglesa, e membro do Núcleo de Estudos de Linguagem e Sociedade da UnB e sócia da Associação Latinoamericana de Estudos do Discurso-ALED. 
a fim de propor uma recontextualização do arcabouço analítico da $A D C$, formulado por Choulariaki e Fairclough (1999).

Palavras-chave: discurso, poder, arcabouço analítico, parto, identidade.

\section{Introdução}

Neste trabalho faço uma releitura do arcabouço analítico da Análise de Discurso Crítica, formulado por Chouliaraki e Fairclough no livro Discourse in late modernity, de 1999. A análise de discurso crítica (doravante $\mathrm{ADC}$ ), desenvolvida inicialmente pelo linguista britânico Norman Fairclough (1989, 1992, 1995, 1999 e 2003), envolve uma visão dialética segundo a qual os discursos não só são moldados pelas estruturas sociais, mas eles também moldam essa estrutura. "O discurso é uma prática, não apenas de representação do mundo, mas de significação do mundo, constituindo e construindo o mundo em significado" (Fairclough, 1992:63).

A palavra discurso relaciona-se etimologicamente com a ideia de curso, percurso, movimento. É a palavra em ação. O discurso não é uma realização individual do sistema linguístico; ele ultrapassa a concepção saussureana de 'parole', pois sua existência social é o seu fundamento. De acordo com Bakhtin (1992), a própria materialidade linguística traz em seu cerne a ideologia e, em decorrência desse pressuposto, a linguagem não pode ser apartada das formas concretas de interação social; ou seja, a comunicação não pode ser separada de sua base material: envolve sujeitos reais em contextos reais que se relacionam no interior de uma cultura e de um panorama sóciopolítico e econômico particular. Nesse sentido, conceber o discurso como parte da prática social implica entender o discurso como um modo de ação sobre a constituição do mundo, como um modo de representação desse mundo e ainda como um modo de identificação dos sujeitos que interagem no mundo (Fairclough, 2003: 28).

A Análise de Discurso Crítica consiste numa abordagem científica transdisciplinar para estudos críticos da linguagem como prática social. O discurso não representa simplesmente a linguagem em 
uso, mas sim em seu uso imbricado nas relações e processos sociais, no sistema de valores e crenças, na constituição das identidades dos sujeitos sociais que interagem na atividade material concreta, sob a forma verbal ou não-verbal.

Dessa maneira, o discurso não é simplesmente uma forma de prática social, mas é considerado como elemento semiótico das práticas sociais, incluindo não só a linguagem, como também a comunicação "para-verbal" (expressões faciais, movimentos do corpo, os gestos), bem como as imagens visuais.

De acordo com Fairclough (2003a) e Chouliaraki \& Fairclough (1999), a proposta da ADC insere-se na tradição da "ciência social crítica", comprometida em oferecer suporte científico para questionamentos sociais relacionados a poder e justiça. A ADC valoriza, então, a transdisciplinaridade como percurso de investigação, especialmente no que tange à compreensão dos fenômenos sociais que têm sofrido profundo impacto com a modernidade tardia. Os autores ressaltam o lugar da ADC no interior dessa análise social mais ampla a qual envolve os processos implicados na pluralidade da vida social e na fragmentação dos sujeitos sociais como processos de natureza linguística: "fragmentação e diferenciação são parcialmente constituídos na proliferação de linguagens" (Chouliaraki \& Fairclough, 1999: 5). Nas palavras dos autores, essa perspectiva teórica "reúne uma variedade de teorias em diálogo, em especial teoria sociais de um lado e teorias linguísticas de outro" (id. Ib.:16). Desse modo, o caráter transdisciplinar da ADC advém do "rompimento de fronteiras epistemológicas" com teorias sociais, por meio do qual constrói sua própria abordagem sociodiscursiva assim como subsidiam os estudos discursivos no bojo das pesquisas sociais (Resende \& Ramalho, 2006: 14).

\section{Histórico da Análise de Discurso Crítica}

Foi na década de 1950 que o linguista estruturalista americano Zellig Harris publicou um trabalho cujo título era Discourse Analysis (Análise do Discurso), em que pretendia investigar estruturas de 
linguagem superiores à frase - unidade básica do estudo gramatical (microlinguística). A ideia de tomar o texto como unidade de análise despertou grande interesse, especialmente na França, no final da década de 60.

Michel Foucault (1987) Mikhail Bakhtin (1992), seguindo essa linha de atuação, foram os primeiros a se dedicarem aos conceitos de 'enunciado' e de 'enunciação'. Foucault destaca que todo enunciado pertence a uma formação discursiva, ou seja, a um "conjunto de regras históricas" em que as condições de exercício da função enunciativa são determinadas. O autor chama a atenção para a diferença entre a frase, como unidade pertencente à esfera da gramática, e o enunciado como unidade do discurso, uma vez que este não é regido apenas pelas leis da língua, mas também pelas leis da lógica de uma formação discursiva (Foucault, 1987:28).

Entender que a enunciação pressupõe uma troca entre o 'eu' e o 'tu' discursivos significa compreender que essa interação não está circunscrita ao contexto imediato da enunciação, mas sim que possui atravessamentos sociais e que foi construída socialmente. Por exemplo, ao tratarmos sobre os tipos de parto, o enunciado "O parto terá de ser uma cesárea" só tem valor e só faz sentido se for proferido em um panorama sócio-histórico-cultural específico no qual alguns pressupostos são inquestionáveis: primeiro, de que é a voz de um especialista da área (o eu do discurso) que está fazendo tal afirmação; segundo, de que a paciente (o tu do discurso) está grávida, prestes a ganhar um bebê; terceiro, de que a prática da medicina permite a realização de um parto cirúrgico, via abdominal; e, quarto, a pressuposição de que a prática cultural dos interlocutores caminha pelo universo da tecnologização da medicina - o enunciado não seria compreensível em uma tribo indígena que não busca a medicina tradicional.

É importante, pois, focalizar a construção dos sentidos sob uma perspectiva múltipla que reúna os sujeitos e os significados, devidamente calcados nos conceitos da historicidade e da ideologia, a fim de não se limitar à ideia da existência absoluta e originária de um 'EU' e de um significado registrado a priori. A partir do momento em 
que passa a integrar um novo paradigma, que contempla a interação com o outro (TU) sob uma ótica dialógica em um cenário mais amplo, o escopo teórico se abre, deslocando para conceitos de sujeito e de sentido que perdem sua centralidade, estabilidade e seu caráter homogêneo e passam a se caracterizar pela heterogeneidade, pelas redes de crenças e valores, pelas diferentes vozes sociais.

O surgimento da Análise de Discurso de vertente francesa associada à tradição intelectual européia que unia as reflexões sobre texto e história coincidiu com o momento em que a Europa conhecia o nome de Bakhtin (Brandão, 200:17). Fruto de uma articulação entre a linguística, o marxismo e a psicanálise, a análise de discurso, conhecida como "linha francesa", na década de 60, nasceu sob essa base interdisciplinar. Além disso, foi influenciada por certa prática escolar que tinha seus pilares assentados na explicação do texto, muito comum na França, à mesma época. Seu quadro teórico preconiza, dessa maneira, uma aliança entre o lingüístico e o sócio-histórico, tendo como conceitos relevantes: (i) a ideologia (com base em Althusser) e o (ii) discurso (com base em Foucault). É sob essa dupla influência que seu grande representante, Michel Pêcheux, foi um dos estudiosos mais profícuos dessa linha. Uma das idéias principais dessa análise de discurso parte da idéia de que o sentido e o sujeito não são toujours déjà-donne (dados a priori), mas são constituídos no discurso. Isso se contrapõe a uma perspectiva idealista da linguagem que seria marcada pela existência espontânea do sujeito (como origem e causa) e pela evidência do sentido. Brandão (2000) chama a atenção para o fato de a linha francesa de análise de discurso partir do pressuposto de que a palavra não existe em si mesma, pois sua existência é determinada pelas "posições ideológicas colocadas em jogo no processo sóciohistórico em que palavras, expressões e proposições são produzidas" (idem, ibidem:62).

Juntamente com essas novas perspectivas de linguagem, a Teoria Social do Discurso foi constituída com vistas a uma abordagem crítico-discursiva de questões sociais. Foi uma proposta, desenvolvida inicialmente por Norman Fairclough, que trouxe influências da Linguística Crítica, desenvolvida na década de 70 por um grupo de 
pesquisadores da Grã-Bretanha que partiam da tradição francesa (Wodak, 2001).

Fairclough escolheu o nome Análise de Discurso Crítica, o qual apareceu pela primeira vez em um artigo, publicado no Journal of Pragmatics, Critical and Descriptive Goals in Discourse Analysis (Fairclough, 1985). No Brasil, a ADC tornou-se conhecida por meio do trabalho de pesquisa da Profa. Izabel Magalhães na Universidade Brasília (UnB), na década de 90. Desde então, pode-se afirmar que a UnB tem sido polo representativo de pesquisas na área, com os trabalhos de Silva \& Vieira (2002); Vieira \& Silva (2003); Silva, Leal \& Pacheco (2009); Resende \& Ramalho (2006 e 2011).

De acordo com Magalhães (2000: 81-2) a principal diferença entre a escola francesa de análise de discurso e a escola britânica está assentada nos papéis do discurso de acordo com uma concepção centrada na reprodução social ou na transformação social. Para a tradição francesa, representada por Michel Pêcheux e influenciada por Louis Althusser, o papel da linguagem e das "representações imaginárias" apóia-se na reprodução das desigualdades entre os grupos sociais. Já a tradição inglesa, a Análise de Discurso Crítica, influenciada por Michel Foucault e Antonio Gramsci, estabelece suas bases em uma visão dinâmica da historicidade "dos gêneros discursos em mutação, observando-se tais mutações como produtos e como elementos constituintes de processos mais amplos de transformação social”.

Adoto, no presente trabalho, a concepção de discurso de Norman Fairclough por considerá-la mais adequada para tempos de globalização e de novas configurações sociais e discursivas concernentes à fragmentação nas identidades dos sujeitos sociais que se relacionam, diariamente, com um grande número de informações.

Assim, sob a ótica da ADC, o discurso se constitui em um sistema de mão dupla: contribui para a constituição das convenções que o restringem, ao mesmo tempo em que é limitado e constituído por essas mesmas convenções. É possível dizer que o discurso é, então, socialmente constitutivo em três aspectos fundamentais: o discurso constrói as diversas posições de sujeito, o discurso constitui também as 
diferentes relações sociais, podendo modificar as existentes por meio de novas formas de interação, e, por fim, o discurso colabora para a construção dos sistemas de conhecimentos e crenças do mundo, além de ser resultante desses três aspectos enumerados (Fairclough 1992).

É por meio dessa perspectiva dialética de discurso que se fundamenta a subjetividade multifuncional em que o sujeito assume variadas posições e se desdobra em diversos papéis sociais. Não só as identidades sociais como também as relações interpessoais são modificadas e inovadas. A criatividade dos sentidos experenciais é afetada por esta visão plural de discurso.

\section{Análise de Discurso Crítica: pressupostos teóricos}

Nesta seção, apresentarei os pressupostos da Análise de Discurso Crítica inserida na ciência social crítica que, por sua amplitude, possibilita um diálogo com outras teorias sob uma perspectiva da pesquisa transdisciplinar (Chouliaraki e Fairclough, 1999).

A modernidade tardia traz, em seu bojo, novas relações entre as experiências e o exercício de reflexão sobre o que é vivenciado. Os avanços na esfera da comunicação e no que concerne às novas formas da tecnologia da informação, somados à moldura cultural da atualidade e à superação das categorias tempo e espaço, marcam essa nova fase da vida social. Em decorrência das transformações em escala global, os indivíduos em seus mundos internos também passam por inúmeras mudanças de ordem identitária, emocional, ideológica e, conseqüentemente, discursiva.

Assim, de acordo com Giddens (2002), os sujeitos têm os seus sentidos de espaço e do seu próprio eu (self) abalados, predominando uma sensação de 'perda de sentido'. Tais modificações não podem ser interpretadas sob perspectivas singulares, uma vez que têm suas raízes assentadas nas naturalizações de interesses particulares, por meio de estratégias particulares, conduzidas por pessoas específicas (grupos sociais particulares) no interior de sistemas característicos. É diante dessa conjuntura que Fairclough e Chouliaraki (1999) 
chamam a atenção para a importância de uma teorização crítica da modernidade tardia a fim de alavancar direções alternativas ainda não experimentadas, o que perpassa certamente o nível da linguagem e do discurso.

As transformações sociais, econômicas, políticas e culturais atingem a esfera global na modernidade tardia, acarretando mudanças na própria identidade dos sujeitos sociais que têm os sentidos de lugar e do 'eu' profundamente afetados, o que tem sido referido, muitas vezes, como uma perda de sentido. Para os autores, as formas sociais - produzidas pelas pessoas e totalmente passíveis de mudanças estão sendo vistas como dadas pela natureza, ou seja, estão sendo naturalizadas. Uma teorização crítica sobre esse momento atual não só pode iluminar o novo mundo emergente, como pode ainda mostrar que direções alternativas existem (Chouliaraki \& Fairclough, 1999: 4).

Chouliaraki \& Fairclough discutem sobre a modernidade tardia no que tange à necessidade de uma análise crítica diante dessa nova fase da vida social e, além disso, destacam qual é o lugar da ADC no interior dessa análise social mais ampla. A motivação primordial da ciência crítica social é contribuir para a consciência desses processos de mudança, e a ADC se inclui nessa linha, apresentando, como diferencial das demais práticas teóricas críticas, a sua ênfase na linguagem. A ADC valoriza, então, a transdisciplinaridade como percurso de investigação, especialmente no que tange à compreensão dos fenômenos sociais que têm sofrido profundo impacto com a modernidade tardia. Segundo Chouliaraki e Fairclough (1999), as construções teóricas do discurso que a ADC se propõe operacionalizar podem advir de diversas disciplinas. Nesse sentido, a operacionalização implica teorizar num meio transdisciplinar em que a lógica de uma teoria pode ser colocada em ação no desenvolvimento de outra, sem que a segunda se reduza à primeira.

O discurso não representa, então, simplesmente a linguagem em uso, mas sim em seu uso imbricado nas relações e processos sociais, no sistema de valores e crenças, na constituição das identidades dos sujeitos sociais que interagem na atividade material concreta, sob a forma verbal ou não-verbal. 
Dessa maneira, o discurso não é simplesmente uma forma de prática social, mas é considerado como elemento semiótico das práticas sociais, incluindo não só a linguagem, como também a comunicação "para-verbal" (expressões faciais, movimentos do corpo, os gestos), bem como as imagens visuais. A noção da vida social constituída de práticas também é uma visão mais abrangente, uma vez que, em estudos anteriores, Fairclough (1992) havia distinguido somente práticas discursivas e práticas sociais.

Visualizar, pois, o discurso como um momento da prática social implica considerar a relação dialética entre as estruturas e os eventos sociais, uma vez que as práticas estão mediando estruturas sociais e ações concretas, ou seja, as estruturas da sociedade são lentamente transformadas por meio das ações reais nas práticas de cada instituição, e vice-versa.

Com essa visão dialética, Chouliaraki \& Fairclough (1999:22) rejeitam tanto a perspectiva do determinismo, que enfatiza a forte estabilidade das estruturas, como o voluntarismo, que superestima o alcance da atividade concreta. Sob esse mesmo foco dialético, conforme mencionado, o discurso pode ser retratado em movimento: ele tanto é moldado pelas estruturas sociais como contribui para sua constituição e reconstituição, seja reproduzindo as estruturas iniciais, seja transformando-as.

Há ainda o elemento da reflexividade que é inerente a toda prática, uma vez que as pessoas sempre produzem representações do que elas fazem como parte daquilo que fazem. De acordo com Chouliaraki \& Fairclough (1999:26), a reflexividade tem dois aspectos essenciais: (i) é alcançada por meio da luta social, visto que o saber sobre as práticas cria posições particulares dentro da própria prática ou fora dela; (ii) a reflexividade de uma prática resulta que todas as práticas possuam um aspecto discursivo irredutível, não só no sentido de que todas as práticas envolvem, em algum grau, a linguagem, como também no sentido de que as "construções discursivas das práticas são em si mesmas partes das práticas".

As práticas possuem, então, três características essenciais: (i) "elas são formas de produção da vida social"; (ii) "cada prática está 
inserida dentro de uma rede de relações com outras práticas” e (iii) "as práticas sempre têm uma dimensão reflexiva: pessoas sempre geram representações do que elas fazem como parte do que elas fazem" (Chouliaraki \& Fairclough, 1999: 22).

Outro aspecto discutido por Chouliaraki \& Fairclough diz respeito à prática teórica, isto é, toda teoria é, ela própria, uma prática, conforme destaquei na introdução do trabalho. Assim como as demais práticas, a teoria está inserida em uma série de relações com as práticas econômicas, sociais, políticas e culturais que determinam sua constituição interna, as quais podem ter efeitos ideológicos que recaem sobre a própria teoria. Os autores ainda destacam que "a pesquisa crítica social é iniciada e terminada no fluxo entre prática teórica e as outras práticas que ela pesquisa (Chouliaraki e Fairclough, 1999: 29). Todavia, os autores lembram que é importante reconhecer a relevância do discurso sem reduzir a vida social a ele; tal reducionismo é um risco constante para os analistas do discurso. Assim, a visão dialética da relação entre o discurso e as facetas extradiscursivas do mundo social é uma visão essencial, especialmente, na modernidade tardia.

\section{Discurso como ação, representação e identificação}

Fairclough (2003), em seu Analysing Discourse, preconiza a análise interdiscursiva do texto em intercâmbio com a ação, com a representação e com a identificação, aspectos que corresponderiam aos "três principais aspectos do significado no texto". Tais elementos estão relacionados, respectivamente, às categorias de gênero, de discurso e de estilo no nível das práticas sociais. Ou seja, a proposta do autor é examinar o caráter interdiscursivo do texto, tomando por base a mistura desses três aspectos, enfocando, de fato, a articulação entre os gêneros, os discursos e os estilos.

Os textos são entendidos, sob essa perspectiva, como partes dos eventos sociais, pois têm a primazia de gerarem efeitos, ao ponto de alterar os conhecimentos, as crenças, as atitudes e os valores. Segundo Fairclough (id. Ibid.: 9), o mundo social é textualmente construído, 
daí a importância de o analista do discurso não perder seu principal objeto, que é a linguagem.

Esse autor define gênero textual como uma concepção relacionada à ideia de ação e de interação linguística, isto é, a uma forma de mudança e transformação. Conforme Fairclough, a mudança de um gênero é parte de transformações mais amplas, sociais, culturais e econômicas. Apresenta, assim, diversas classificações de gênero para ilustrar essa idéia de gênero em movimento. Essa característica fluida dos gêneros deve estar associada ao hibridismo que poderá estar presente também nos discursos e nos estilos.

Sobre o segundo aspecto, o discurso como representação, deve-se compreender que representar determinados aspectos do mundo (físico, social, psicológico) pode assumir um tom imaginário, projetivo. Um único discurso poderá gerar muitas representações específicas, e devemos não confundir cada uma dessas representações com o que se chama 'discurso'. Desse modo, poderemos dizer que um texto apresenta o discurso da medicina convencional ou o discurso da medicina alternativa, ou ainda, o discurso da humanização do parto em conformidade com as representações de mundo encontradas ao longo do texto.

Como terceiro ponto, Fairclough (2003) destaca a constituição das identidades sociais e individuais dos falantes nos eventos dos quais fazem parte. O estilo é considerado como analiticamente distinto dos aspectos anteriores, embora seja dialeticamente interconectado com cada um deles. Os estilos, segundo o autor (idem, ibidem:159), são os aspectos discursivos dos modos de ser, das identidades. Ressalta também que 'quem a pessoa é' passa a ser parcialmente uma questão de 'como a pessoa se expressa', o modo como fala e escreve, a maneira como se apresenta, como se movimenta etc. Assim, Fairclough (2003:159-160) acredita que o que as pessoas colocam nos textos é um importante indício de como se auto-identificam na 'texturização' das identidades. E é sob esse prisma que o autor defende a relação existente entre identidade social e identidade pessoal, destacando como tal relação pode ser descortinada pela análise textual, por intermédio do estudo da modalidade textual, por exemplo. 
Os três tipos de significação em um texto, quais sejam ação, representação e identificação, são, pois, trabalhados nesta última obra de Fairclough. O autor utiliza algumas categorias da Linguística Sistêmica Funcional, proposta por Halliday (1985), como apoio para as análises apresentadas, assim como não lança mão de outras metodologias de análise linguística (categorias da Pragmática, da Análise da Conversação...), pois, segundo ele, a ADC é um método que pode se apropriar de outros meios.

Fairclough destaca que nosso conhecimento será sempre parcial e incompleto e que, uma vez cientes de que estamos constantemente procurando ampliar e aperfeiçoar tal conhecimento, devemos aceitar que nossas categorias não são definitivas. $\mathrm{O}$ autor (2003:15) ainda chama atenção para o fato de que os analistas do discurso não podem reduzir suas análises aos aspectos textuais, o que seria limitado, visto que excluiria a forma como os sentidos são produzidos no texto, os efeitos causais desses sentidos e o matiz ideológico ali presente.

\section{Uma breve reflexão teórica acerca da identidade}

A questão da identidade tem sido recorrentemente discutida a partir do reconhecimento de uma mudança nas velhas identidades em declínio e, consequentemente, do reconhecimento de um sujeito moderno fragmentado, não unificado como até então se analisava (Hall, 2000).

Essa mudança na concepção de identidades está inserida em um amplo processo de mudanças centrais nas sociedades modernas. A tese fundamental é a descentralização das identidades modernas, o que acarreta questões contraditórias, abordadas por Hall (2000).

O conceito de identidade é bastante complexo e, vem, pouco a pouco, sendo desenvolvido pela ciência social contemporânea. As transformações estruturais que assaltam as sociedades modernas a partir do final do século XX demonstram que as paisagens culturais de gênero, etnia, raça, classe, sexualidade e nacionalidade que, no 
passado, forneciam sólidas posições para os indivíduos sociais, hoje estão sendo questionadas. Nesse sentido, nossas identidades pessoais são também repensadas, uma vez que o que anteriormente era visto como uma auto-identidade clara e estável, atualmente, é percebida como descentrada e heterogênea.

É no contexto dessas transformações que o sujeito moderno passa por descentramentos (Hall, 2000) sobre os quais destaco, sucintamente, os seguintes pontos. Dois desses descentramentos são particularmente relevantes para a questão aqui levantada. $\mathrm{O}$ primeiro deles refere-se às contribuições do trabalho do filósofo e historiador M. Foucault. Em sua 'genealogia do sujeito moderno', Foucault destaca o poder disciplinar como altamente regulador, cujo objetivo está na permanência da vigilância e controle das novas instituições desenvolvidas no século XIX: escolas, prisões, hospitais, etc. O interessante dessa perspectiva é a contradição inerente ao desenvolvimento da sociedade moderna: quanto mais a natureza institucional é organizada (regimes disciplinares), mais o sujeito se individualiza em uma constante vigilância e isolamento.

Outro descentramento está no impacto recente do feminismo, que emergiu nos anos sessenta e questionou paisagens da vida como família, trabalho, divisão doméstica, cuidado com filhos, etc. Além disso, o movimento feminista enfatizou questões políticas e sociais ligadas à subjetividade, à identidade e ao processo de identificação (como mãe/ pai, mulher/homem, esposa/o e filha/o). Foi uma contestação da posição social da mulher rumo à formação das identidades de gênero, questionando a categorização de homens e mulheres como dicotomias da mesma identidade.

Esses dois aspectos são relevantes para a reflexão que proponho ser feita neste trabalho. Por um lado, há o processo de medicalização do parto, que, pouco a pouco, se 'infiltrou' na cultura e na sociedade e tomou conta dos nascimentos da humanidade. Com essa medicalização, não só a figura do médico tornou-se fundamental, como também todo o aparato da medicina que, seguindo um pensamento foucaultiano, passou a controlar e impor certos regimes próprios de um patamar dominador, disciplinador. 
Desse modo, vivemos hoje transformações profundas não só concernentes ao nosso próprio sentido do 'eu', que se encontra sustentado pelo reconhecimento da fragmentação do sujeito, como também concernentes ao nosso sentido de tempo e lugar, em que a fugacidade e a efemeridade configuram a ordem do dia.

De acordo com Bauman (2001:93), a sociedade pós-moderna envolve seus sujeitos primariamente em sua condição de consumidores, e não de produtores. Seguindo essa linha de raciocínio, o autor ressalta que a vida é organizada em torno do consumo, orientada pela sedução, pelos desejos e pela ideia de que não existem regras para transformar os desejos de hoje em necessidades de amanhã. Sobre o significado de saúde e de corpo saudável, o autor ressalta que:

o status de todas as normas, inclusive a norma de saúde, foi severamente abalado e se tornou frágil, numa sociedade de infinitas e indefinidas possibilidades. O que ontem era considerado normal e, portanto, satisfatório, pode ser considerado preocupante, ou mesmo patológico, requerendo um remédio. (...) Quase qualquer cura apresenta grandes riscos, e mais curas são necessárias para enfrentar as conseqüências de riscos assumidos no passado.

Também Giddens (2001) aborda, em sua obra Modernidade e Identidade, alguns aspectos norteadores da reflexão que proponho neste trabalho. Segundo ele, a modernidade é uma cultura do risco em que as certezas da tradição e do hábito foram substituídas pela dúvida e pela transformação do conhecimento em hipóteses. Neste contexto, as noções de confiança e risco são particularmente importantes. A confiança básica está relacionada com um senso precoce de segurança ontológica, precoce no sentido de ser desenvolvido nos seres humanos em sua mais tenra infância a partir do relacionamento mais primitivo do homem, qual seja, o vínculo maternal, ou o vínculo com aquela pessoa que assume o papel "maternal" de proteção contra ameaças e perigos externos. Quando Giddens se refere ao risco da vida moderna, não quer com isso dizer que a vida na modernidade é mais arriscada que em tempos pré-modernos. Para ele, o risco se liga à contínua construção reflexiva do eu e do conhecimento; isto é, o futuro é 
constantemente trazido para o presente por meio da reflexividade, acompanhado da incerteza e da dúvida.

Desse modo, na ordem da modernidade tardia, a auto-identidade torna-se reflexivamente organizada, no sentido de que "cada um de nós não apenas 'tem', mas vive uma biografia reflexivamente organizada em termos de fluxo de informações sociais e psicológicas sobre possíveis modos de vida" (Giddens, 2001: 20). A pergunta "como devo viver" faz parte do projeto reflexivo do eu baseado em narrativas biográficas coerentes, que são continuamente revisadas.

Outro aspecto importante, destacado por esse autor, refere-se à construção dos sistemas abstratos que dizem respeito aos sistemas de conhecimento técnico que, na vida moderna, afetam profundamente a vida cotidiana dos indivíduos. Os sistemas abstratos encontram-se envolvidos não somente "na ordem institucional da modernidade, mas também na formação e continuidade do eu" (Id. Ibid.: 37). É exatamente sobre essa relação entre os sistemas especializados de conhecimentos e construção, e as mudanças na auto-identidade, que me interessa refletir, pois, segundo Giddens, os sistemas especializados, incluindo a medicina e seu aparato cognitivo, compõem um tipo de mecanismo de desencaixe da modernidade. Tais mecanismos de desencaixe representam a idéia de descolamento das relações sociais dos seus contextos usuais (em uma visão pré-moderna) e sua rearticulação sob a influência da indeterminação do espaço-tempo, característicos da modernidade. Essa reflexão em torno dos mecanismos de desencaixe sob a forma de sistemas especializados é relevante no sentido de que o tempo e o espaço tornam-se menos importantes diante da validade dos conhecimentos técnicos, independentemente dos sujeitos que deles fazem uso (Id. Ibid.: 24).

Dessa maneira, a questão da identidade e da diferença está, hoje, no centro da teoria social e da prática política, e encontrase "na tensão entre perspectivas essencialistas e perspectivas nãoessencialistas sobre identidade" (Woodward, apud Silva, 2000: 12). Uma visão essencialista busca identificar o que existe de universal (a essência) nos grupos sociais; ou seja, procura aquilo que não se altera durante o tempo e que é utilizado para distinguir um grupo de 
outro. Por outro lado, uma perspectiva não-essencialista de identidade inclui uma reflexão sobre a diferença, enfatizando o caráter flexível e fluido das identidades. A identidade é considerada, então, como construção, como um efeito, instável, fluida, contraditória, inacabada e fragmentada (Silva,2000).

Neste sentido, é importante destacar que tanto a identidade quanto a diferença são produtos culturais e sociais; são criações discursivas e são constituídas por meio da linguagem. A natureza da linguagem que usamos, conseqüentemente, exerce implicações nos modos como as subjetividades são construídas e produzidas, acarretando novas formas de se perceber e de perceber o outro. Segundo Silva (2000:82):

a afirmação da identidade e a marcação da diferença implicam, sempre, as operações de incluir e de excluir. Dizer 'o que somos' significa também dizer 'o que não somos'. A identidade e a diferença se traduzem, assim, em declarações sobre quem pertence e sobre quem não pertence, sobre quem está incluído e sobre quem está excluído. Afirmar a identidade significa demarcar fornteiras, significa fazer distinções (...) está sempre ligada a uma forte separação entre 'nós' e 'eles'.

Sob a perspectiva não essencialista de identidade, Hall (2001) destaca que os indivíduos constroem o mundo e a si próprios por meio de uma identidade relacional e instável. Sob esta ótica, a resposta à questão "Quem nós somos" depende dos eventos discursivos dos quais participamos. $\mathrm{O}$ autor compreende a identidade como um ato performativo, entendendo os indivíduos não com base em alguma essência, mas como sujeitos que se constituem nos discursos e as identidades como construídas nos eventos discursivos.

\section{Ideologia e poder}

A concepção da linguagem no âmbito da Análise de Discurso Crítica assume uma perspectiva interacional entre a linguagem e a sociedade, de modo a superar um olhar neutro sobre as trocas 
linguísticas e a superar uma visão estanque da estrutura da língua, de um lado, e dos sujeitos sociais, de outro. Essa perspectiva interacional se apóia em uma troca dialética entre esses dois pólos, de modo que o discurso configura uma prática em articulação com outras práticas. É importante ressaltar que todos os elementos que compõem tais práticas sociais se retroalimentam, se interpelam, se interrogam. Segundo L. Iñiguez (2004:94):

os discursos não emanam do interior de sujeitos, nem tampouco são uma inoculação ideológica que determine o pensamento desses mesmos sujeitos. Os discursos articulam o conjunto de condições que permitem as práticas: constituem cenários que passam a facilitar ou a dificultar as possibilidades que fazem surgir regras e mantêm relações.

Desse modo, tanto a linguagem como a realidade social possuem seus mecanismos específicos de estruturação e de realização. Todavia, as influências recíprocas de constituição que entrelaçam essas duas dimensões são aspectos fundamentais na tessitura da prática. No contexto analisado na minha pesquisa doutorado, por exemplo, foi possível detectar esse diálogo entre as práticas sociais e a linguagem, especialmente no contexto atual de tantas modificações nos paradigmas do parto. Quando um médico se insere em uma realidade social e ideacional mais naturalista, uma série de modificações ocorre em diversos níveis, desde o mais material, como o tempo de espera no quarto do hospital, antes de se deslocar para a sala de parto, assim como no vestuário do médico durante as consultas, na decoração do ambiente, na relação menos assimétrica com a parturiente. Tais mudanças são refletidas e retroalimentadas pelos usos discursivos da interação com esse mesmo médico, até mesmo na escolha lexical: por exemplo, ele passa a utilizar o termo "bebê", no lugar de "feto" ou "massa fetal".

Dessa maneira, ao assumir como princípio o entendimento de que a linguagem não é neutra e nem se constitui à parte da realidade social, proponho uma análise que contemple o discurso inserido nas relações de poder como hegemonia. De acordo com Gramsci (1971), as lutas hegemônicas pelo poder estão baseadas em mudança de foco 
das relações de dominação, as quais passaram a ser mais calcadas no consentimento ao invés de ter como base a coerção. Essa visão de hegemonia envolve a naturalização das práticas sociais e do relacionamento entre as práticas como aspectos do senso comum, isto é, aspectos dados como 'naturais' e 'neutros'. A manutenção dessas relações de dominação é guiada pelas ideologias dominantes. A hegemonia, todavia, nunca é estável, uma vez que é constituída nas relações de luta pelo poder, possuindo, pois, uma estabilidade relativa nas articulações dos momentos sociais. Essa visão destaca a "inerente possibilidade de desarticulação e rearticulação" (Chouliaraki \& Fairclough, 1999:24-5).

No que se refere ao debate sobre ideologia, refaço um percurso de reflexão realizado por Fairclough (2001: 116-7) a fim de compreender os pilares de um entendimento mais atual e crítico da constituição das ideologias de dominação. O autor considera três asserções propostas por Althusser (1971) para destacar as fontes primeiras de seu raciocínio. A primeira proposta althusseriana defende a idéia de que a ideologia possui existência material nas práticas sociais das instituições. Em segundo lugar, está a afirmação de que a ideologia 'interpela os sujeitos', o que se relaciona aos efeitos ideológicos na constituição dos sujeitos. E, finalmente, encontra-se a "asserção de que os 'aparelhos ideológicos do estado' (instituições, tais como a educação ou a mídia) são ambos locais e marcos delimitadores na luta de classe, que apontam para a luta no discurso."

Apesar de considerar as três proposições althusserianas sobre a ideologia, Fairclough deixa claro que considera o exagero desse autor na constituição ideológica dos sujeitos, de modo a subestimar as possibilidades de luta e de mudança. A ideologia, vista sob essa perspectiva limitadora, "figura como um cimento social universal" e sugere ainda um equilíbrio na lutas dos aparelhos ideológicos do estado, o que, para Fairclough (1992:117) constitui um ideal inatingível. "O equilíbrio entre sujeito efeito ideológico e sujeito agente ativo é uma variável que depende das condições sociais” (id. Ibid.:121).

Assim, Fairclough (1992:119) analisa a relação entre a linguagem e a ideologia, argumentando que a ideologia investe a linguagem em 
vários níveis. A localização da ideologia se dá tanto nas estruturas que constituem o resultado dos eventos passados, bem como as condições existentes para os eventos atuais, "como nos próprios eventos quando reproduzem e transformam as estruturas condicionadoras".

Segundo John Thompson em seu livro Ideologia e cultura moderna (1995), as ideologias são caracterizadas por relações de dominação. Elas caracterizam as práticas discursivas na medida em que incorporam sentidos que contribuem para manter ou reestruturar relações de poder.

Thompson (1995) distingue dois tipos de concepção de ideologia: (i) as concepções neutras, em que as ideologias são consideradas aspectos da vida social sem relações necessariamente ilusórias e enganadoras; e também (ii) as concepções críticas, que trazem um sentido negativo, baseado em projetos de dominação.

A análise da ideologia proposta pela ADC interessa-se por esse último sentido, ou seja, pelos modos como as formas simbólicas se relacionam com o poder, ou nas palavras do autor, pela

maneira como o sentido serve para estabelecer e sustentar relações de dominação: estabelecer querendo significar que o sentido pode criar ativamente e instituir relações de dominação; sustentar querendo significar que o sentido pode servir para manter e reproduzir relações de dominação através de um contínuo processo de produção e recepção de formas simbólicas (Thompson, 1995: 79; os destaques são do autor).

Há, dessa forma, três pontos essenciais nessa concepção de ideologia: a noção de sentido, a definição de dominação e as formas pelas quais o sentido pode estabelecer e sustentar as relações de dominação. Na concepção de Thompson (1995:79), 'sentido' está relacionado às formas simbólicas que são "ações, falas, imagens e textos produzidos por sujeitos e reconhecidos por eles e por outros construtos significativos". As formas simbólicas se encontram em processos e contextos estruturados socialmente. Para o autor, as relações de dominação estão vinculadas às relações de classe, sexo e etnia, bem como às relações entre o indivíduo e o Estado. 
Haverá "dominação quando as relações estabelecidas de poder são sistematicamente assimétricas" (id. Ibid.:80).

Há, pois, inúmeros modos pelos quais os sentidos podem estabelecer e sustentar relações de dominação. Thompson (1995) classificou-os em cinco modos (legitimação, dissimulação, unificação, reificação e fragmentação) e em cada um deles especificou as estratégias típicas de construção simbólica. Descrevo a seguir, sucintamente, estes modos e seus mecanismos; exemplifico, alguns mecanismos com trechos dos dados da minha pesquisa de doutorado.

A legitimação apresenta as relações de poder e as assimetrias sociais como legítimas, justas e dignas do apoio geral. As estratégias desse modo de operação são a racionalização caracterizada por uma lógica de raciocínio para persuadir os sujeitos; a universalização em que certos acordos particulares são apresentados como se fossem em benefício de todos; e, por fim, a narrativização que se baseia em histórias que narram o passado como parte de uma tradição eterna e aceitável. No exemplo a seguir, por meio da racionalização, uma médica obstetra constrói uma cadeia de argumentações favoráveis para o uso da manobra de kristeller (procedimento de parto agressivo e condenado pela Organização Mundial de Saúde).

\section{Exemplo de legitimação - racionalização (argumentação da médica):}

"O que eu gosto às vezes de fazer é uma compressão de linha do fundo do útero leve, só um apoio, um suporte, por que tem mãe que fica muito cansada no final, que não consegue."

$\mathrm{Na}$ dissimulação, as causas reais dos fenômenos são ocultadas e obscurecidas. As formas simbólicas estão marcadas pelas seguintes estratégias: deslocamento que consiste na transferência estratégica das causas e dos sentidos para outros focos que não são verdadeiros; eufemização que é uma estratégia de enfraquecimento na descrição de relações ou ações sociais; e tropo que engloba a sinédoque, a metonímia e a metáfora - todas dissimulando relações de dominação. 
A unificação é uma forma de unidade que relaciona os sujeitos numa identificação coletiva, ignorando as suas diferenças individuais. As estratégias são a padronização e a simbolização. A primeira é uma maneira de adaptar todas as formas simbólicas a um único padrão; um exemplo está no estabelecimento de uma linguagem nacional criando uma identidade coletiva padronizada. A segunda estratégia - a simbolização da unidade - compreende a criação de símbolos de unidade e de identificação coletiva, tais como bandeiras, hinos, emblemas, entre outros.

\section{Exemplo de unificação - padronização, nas palavras da gestante:}

"Ela (a médica) disse que não tem problema em tentar (parto normal), mas ela disse que eles (os médicos) dão um tempo pra ver se nasce (...) se não nascer, eles não dão mais chance." (G7)

$\mathrm{Na}$ fragmentação, a ideologia opera na segmentação de indivíduos que são considerados como um desafio aos grupos dominantes. A diferenciação e o expurgo do outro são duas estratégias que desunem alguns sujeitos da coletividade, apresentados como uma ameaça ou um inimigo do bem-estar geral.

\section{Exemplo de Fragmentação - expurgo do outro, nas palavras de uma médica:}
"Doula? Destesto. Nem sei se tem alguma formação. Elas fazem a cabeça das pacientes que ficam exigentes, trazem plano de parto, contrato de como elas querem o parto.." (M 5)

O último modo de operação da ideologia é a reificação, em que as relações de dominação são estabelecidas e sustentadas por meio da retratação de uma situação transitória como se fosse permanente e atemporal. As estratégias compreendem a naturalização, a eternalização, a nominalização e a passivização. Na primeira delas, um estado de coisas é considerado como algo natural ou como 
resultante inevitável de características naturais. Um exemplo claro da naturalização está na divisão do trabalho entre homens e mulheres baseada em suas características fisiológicas. No universo da parturição, percebemos esta estratégia sendo utilizada para convencer as mulheres a ganharem bebê deitadas como se esta fosse a posição 'natural' para se parir uma criança; ou ainda, argumenta-se que a episiotomia é uma necessidade no Brasil em decorrência da estatura das mulheres.

\section{Exemplo de reificação (naturalização), nas palavras da médica:}

"a mulher européia tem um períneo enorme, elas são altas, tem mais espaço para ganhar o bebê. Já as brasileiras são pequenas, precisam da episio" (M5).

Com relação à segunda estratégia - a eternalização - os fenômenos sociais são esvaziados do seu caráter histórico e são apresentados como permanentes, imutáveis e recorrentes, assim, costumes e tradições ligados a um passado são inquestionáveis.

$\mathrm{E}$, finalmente, a nominalização e passivização consistem em recursos de nível gramatical e sintático, os quais marcam, respectivamente, o apagamento da ação na retratação discursiva dos acontecimentos sociais.

A ideologia marca, enfim, as práticas discursivas das sociedades cujas relações de dominação são estruturadas por sujeitos sociais capazes de agir e transcender as próprias ideologias. A ideologia está, pois, tanto nas estruturas, como nos eventos, operando de forma a reproduzi-los ou a transformá-los.

\section{Repensando o arcabouço da ADC}

Repensar o arcabouço da ADC, proposto por Chouliaraki e Fairclough (1999) foi algo que surgiu no decorrer das análises dos dados da pesquisa de doutorado, em função de algumas reflexões baseadas 
nas orientações dos próprios autores. Chouliaraki e Fairclough sugerem que o arcabouço da ADC é um instrumento que pode ser adaptado à realidade de cada análise, o que torna possível a seleção dos tópicos que interessarem ou, até mesmo, a inversão e a exclusão de outros. Com base nessa primeira leitura, selecionei os itens do arcabouço que seriam viáveis para a análise específica que estava realizando no momento. Posteriormente, ampliei a reformulação do arcabouço de modo que ele seja um instrumento fundamentado na nossa prática social e cultura particular e capaz de abranger uma gama variada de pesquisa.

Nesta releitura, optei por modificar o tópico (2), unificando o item 'b' e 'c' e propondo um novo item para 'c', qual seja, a "análise das identidades”, em função da relevância teórica desse aspecto da vida social nas pesquisas em ADC. Resolvi retirar o tópico (3), "Função do problema na prática", e o substituí por "Definindo os principais obstáculos", com base na afirmação dos autores de que, a partir das análises realizadas no tópico (2), seria viável e possível o analista enumerar os principais desafios encontrados nos itens "a", "b" e "c". Por fim, desdobrei o último tópico (5), Reflexões na análise, em dois outros: em (5) "Reflexões sobre a análise” e em (6) "Reflexões finais sobre o problema”, por acreditar que assim as reflexões finais acerca da questão e da própria análise se organizam de modo mais detalhado.

Apresento o arcabouço original (Chouliaraki e Fairclough, 1999:60) para que seja possível realizar as comparações entre as propostas:

\begin{tabular}{|l|l|}
\hline 1) Problema & 1) Questão motivadora \\
(atividade, reflexividade) & 2) Aprofundando a questão: \\
2) Obstáculos a serem & a) Análise da conjuntura; \\
resolvidos: & b) Análise do discurso: \\
a) Análise da conjuntura; & (i) Análise interdiscursiva \\
b) Análise da prática em foco (em & (ii) Análise linguística \\
$\begin{array}{l}\text { que o discurso é um momento) } \\
\text { (i) Prática (s) relevante (s)? }\end{array}$ & c) Análise das identidades \\
$\begin{array}{l}\text { (ii) Relação do discurso com os } \\
\text { demais momentos? }\end{array}$ & $\begin{array}{l}\text { 3) Definindo os principais } \\
\text { desafios }\end{array}$ \\
\hline
\end{tabular}



- discurso como parte da atividade;
- discurso e reflexividade;
figurando a questão
c) Análise do discurso:
(i) análise estrutural: a ordem de discurso;
(ii) análise interacional
- análise interdiscursiva
- análise lingüística e Semiótica
3) Função do problema na prática
4)Possíveis formas de vencer os obstáculos
5) Reflexões sobre a análise
5) Refletindo sobre a análise

No decorrer do processo de elaboração das análises e da escrita da tese, optei por alterar um pouco mais essa primeira releitura. Dessa forma, cheguei a um modelo final, o qual denominei "Proposta de um novo arcabouço”. Diante dos dados concretos de pesquisa e do contexto real de análise, percebi o quanto seria útil realizar algumas modificações no arcabouço original. Por meio de reflexões e diálogos com colegas e professores, cheguei, enfim, a esta última versão, na qual proponho as seguintes mudanças:

1. Troca da denominação "Problema" por "Questão motivadora" (tópico 1);

2. Inclusão da Análise das Identidades no item "c" do tópico 2;

3. Retirada dos tópicos "Função do Problema na prática" e "Possíveis formas de vencer os obstáculos";

4. Elaboração do tópico 3: "Definindo os principais obstáculos";

5. Desdobramento do último tópico do original em dois tópicos diferentes: (4) Refletindo sobre a Análise e (5) Reconfigurando a Questão. 
Apresento a seguir apenas a proposta de arcabouço analítico para ADC e explico cada um dos tópicos elencados.

\begin{tabular}{|l|}
\hline 1) Questão motivadora \\
2) Aprofundando a questão: \\
a) Análise da conjuntura; \\
b) Análise do discurso: \\
(i) Análise interdiscursiva \\
(ii) Análise linguística \\
c) Análise das identidades \\
\hline 3) Definindo os principais desafios \\
\hline 4) Reconfigurando a questão \\
\hline 5) Refletindo sobre a análise \\
\hline
\end{tabular}

\section{1) Questão motivadora:}

De acordo com a proposta de Chouliaraki e Fairclough (1999), a percepção de um problema relativo ao discurso na vida social compõe o primeiro ponto para que uma análise seja considerada como necessária.

Chouliaraki e Fairclough (1999) alegam que o problema elencado pode ser localizado na própria prática social focalizada, ou seja, na atividade concreta, ou pode estar na construção reflexiva da prática social, ou seja, nas representações que os sujeitos fazem de suas atividades que são, elas próprias, partes constitutivas de tais atividades.

A substituição da nomenclatura 'problema' para 'questão motivadora' será produtiva no sentido de retratar o aspecto selecionado para a pesquisa sem enquadrá-lo, de antemão, como problemático. Depois que o analista finalizar o segundo tópico do arcabouço definindo os principais desafios- ele será capaz de afirmar, com base em uma análise concreta e teoricamente sustentada, se a questão 
selecionada, de fato, faz parte da agenda a ADC. A substituição está assentada na argumentação central de que as análises que são realizadas, no seio do arcabouço de Chouliaraki e Fairclough (1999), não podem ser encaixadas na agenda da ADC se não se configurarem como um problema na prática social ou na prática reflexiva. Essa mudança é respaldada, enfim, por uma atitude cautelosa por parte do próprio analista do discurso, o qual, por meio de sua análise, após o segundo passo do arcabouço, confirmará ou não o caráter problemático da questão motivadora e, nesse momento, ela poderá ser chamada de 'problema'.

\section{2) Aprofundando a questão motivadora}

A fim de analisar um aspecto discursivo da vida social considerado, sob alguma ótica, como foco de interesse, é necessário ampliar o olhar analítico, o que será feito a partir das três análises propostas no arcabouço, para entender as razões motivadoras e as implicações estruturais da questão focalizada.

Assim, destaco três tipos de análise fundamentais para orientar o cumprimento da tarefa do tópico 2 'aprofundando a questão motivadora': primeiramente, uma análise conjuntural pode esclarecer o quadro da prática social em que o discurso se localiza. Essa análise envolve o cruzamento entre instituições, vozes e materiais que compõem tal prática social. É uma análise contextual comprometida a ir além da descrição estanque do tempo e do espaço que enquadra o problema; ela propicia uma visão tridimensional ao priorizar o entrelaçamento dos fatores múltiplos que caracterizam a prática em foco.

A conjuntura pode ser mais ou menos complexa dependendo do número e da combinação das práticas mais ou menos extensas (Chouliraki \& Fairclough, 1999:22). Um dos objetivos da análise da conjuntura é localizar o discurso analisado no tempo real de forma a relacioná-lo com os processos de produção e de consumo, considerando a diversidade de interpretações. Todavia, é importante refletir sobre os mecanismos históricos atuantes na questão de pesquisa. Perceber, por exemplo, as raízes históricas de práticas cristalizadas e ainda presentes 
nos dias atuais é uma reflexão pertinente para a compreensão da conjuntura focalizada.

A segunda análise prioriza um olhar assentado na linguagem; trata-se da análise do discurso propriamente dita. É baseada na suposição de que a linguagem é uma parte irredutível da vida social, dialeticamente interconectada com outros elementos da vida social, de modo que a análise e pesquisa social sempre têm a ver com linguagem (Fairclough 2003). A análise de discurso com duplo foco na estrutura e na interação possibilita, pois, um aprofundamento lingüístico no problema focalizado na pesquisa.

E, finalmente, a terceira análise focaliza um estudo acerca das identidades, a partir da qual é possível compreender os diferentes papéis sociais assumidos pelos sujeitos nas diferentes posições das práticas sociais em foco. Chouliaraki e Fairclough (1999) ressaltam que a incerteza das identidades é considerado um dos temas mais difundidos na modernidade tardia.

Do ponto de vista metodológico, a análise das identidades encontra-se, prioritariamente, no bojo da análise discursiva. Todavia, essa etapa pode contar com uma articulação como a etnografia crítica, por exemplo, ou outra metodologia que auxilie o pesquisador a realizar a análise das identidades. O diário de campo, as narrativas dos sujeitos de pesquisa e as entrevistas abertas são excelentes instrumentos para coletar dados textuais dos participantes para análise de identidades coletivas e individuais (Silva e Vieira, 2002)

Além disso, um olhar analítico sobre as construções de autoidentidade possibilitará um entendimento das atividades reflexivas do indivíduo em suas rotinas. Diferentemente da identidade que ainda supõe continuidade do tempo e no espaço, a auto-identidade tem essa continuidade reflexivamente interpretada pelo agente. "Em outras palavras, se questionados, os agentes são normalmente capazes de fazer interpretações discursivas da natureza e das razões do seu comportamento” (Giddens, 2000:39). Essa é uma análise particularmente relevante porque ela complementa uma visão do contexto e do discurso a partir de um olhar para o sujeito que vive no contexto tal e que se submete a um discurso ' $x$ ' ou ' $y$ '. 


\section{3) Definindo os principais desafios}

Após realizar as três análises do tópico anterior, é possível, ao analista, enumerar de modo mais claro e consistente, quais são os desafios que a questão em foco apresenta na prática. Parte-se, desse modo, de parâmetros concretos e não apenas de hipóteses para que o pesquisador possa refletir sobre a própria análise e, em seguida, sobre a própria questão inicial.

Nessa fase, há um redirecionamento da análise científica social com base na lógica relacional para a baseada na lógica dialética. Isso significa que, nessa etapa da análise, interessa não mais focalizar a estabilidade relativa das práticas, mas sim analisar a estabilidade como um efeito de poder e como um fator de reprodução das relações assimétricas, cujo foco recai sobre a tensão dialética entre as estruturas e as atividades práticas das pessoas engajadas na prática social em foco. Essa etapa é marcada por uma troca daquilo que "é” para o que "deveria ser", ou seja, a troca da explicação usual sobre a questão para uma avaliação da questão em termos dos resultados problemáticos, isto é, do que deveria mudar (Chouliaraki \& Fairclough, 1999:32).

\section{4) Refletindo sobre a análise}

Nessa etapa insere-se a relação entre a prática teórica do analista e as práticas 'práticas' analisadas. Todo pesquisador parte de uma determinada posição dentro do campo teórico, possuindo um interesse de conhecimento particular que acarreta, conseqüentemente, perspectivas orientadas para problemas, poder, ideologia etc. Uma pesquisa crítica social pode ser reflexiva no sentido de inserir uma reflexão sobre o ponto de vista a partir do qual a pesquisa é efetuada.

De acordo com Chouliaraki \& Fairclough (1999:66), a especificidade de perspectiva não é em si negativa, desde que tal especificidade esteja clara e desde que outras perspectivas sejam reconhecidas.

Considero, particularmente, essa etapa singular nesse arcabouço analítico, tendo em vista que, como pesquisadora, incluo as construções reflexivas que ocorreram no decorrer desta pesquisa. Assumir um posicionamento como sujeito participante da pesquisa crítica acredito 
ser fundamental em uma prática teórica comprometida com ação crítica. Nesta etapa, retomam-se as questões iniciais e os objetivos traçados antes da análise a fim de (re)localizá-los com mais suporte teórico e analítico, por meio de uma auto-avaliação dos mesmos.

\section{5) Reconfigurando a questão:}

O objetivo nesta etapa é discernir os recursos que são possíveis para modificar as coisas em seus modos de ser usuais. O foco desta etapa ultrapassa as estruturas reprodutivas para ressaltar os percursos que as pessoas fazem em determinadas condições estruturais. $O$ importante é focalizar as estruturas como sistemas abertos para a ação transformadora, o que geralmente caracteriza-se pelas tensões e contradições no interior de uma prática, em ocasiões particulares.

O que interessa, então, é retomar a questão inicial que foi destacada, caracterizada e analisada ao longo de todo o processo proposto pelo arcabouço, para finalmente ser possível a visualização de novos aspectos não antes vislumbrados. É importante, portanto, destacar os caminhos que se abriram a partir da análise feita a fim de que uma visão inovadora da questão inicial seja lançada no mundo social.

\section{Narrativa de pesquisa: como aplicar o arcabouço metodológico da ADC}

Ao propor estas modificações no arcabouço da ADC, optei por aplicá-lo de forma especialmente diluída ao longo da minha tese de doutorado por considerar que dados e análise mantêm entre si uma relação dialética. Ao longo dos capítulos da pesquisa, trabalho com os passos do novo arcabouço a fim de conferir utilidade ao instrumento que me foi tão válido para visualizar e compreender os dados. O arcabouço recontextualizado pode ser aplicado na própria organização das seções do gênero acadêmico (monografia, artigo 
científico, dissertação, tese); não é necessário que o arcabouço apareça somente na seção analítica, uma vez que o entendimento acerca do fio condutor da análise realizada, sua lógica e sincronicidade são elementos presentes na produção acadêmica como um todo.

Utilizo, apenas com a finalidade de exemplificar, a organização e a aplicação do arcabouço na minha tese de doutorado. No capítulo um, focalizei os caminhos metodológicos e teóricos que nortearam a pesquisa. Apresentei a questão motivadora, os pressupostos teóricos da Análise de Discurso, especialmente da Análise de Discurso Crítica, estudos sobre identidade e reflexões acerca do poder e da ideologia como forma de dominação. Destaquei, ainda, os objetivos do trabalho, comentei as questões de pesquisa, bem como o novo aparato metodológico que subsidiou as práticas de pesquisa.

No segundo capítulo, desenvolvi a primeira parte do item 2 do arcabouço "Aprofundando a questão", mais especificamente o ponto relativo à conjuntura histórica. Apresentei alguns percursos da historicidade do parto, resgatando o simbolismo presente nas mitologias grega e romana, no discurso da Gênese e do Êxodo, bem como analiso o que foi legitimado como história da parturição. Neste contexto, destaquei o modo como o parto era considerado e vivenciado em diferentes culturas e como, ao longo do tempo, foi-se modificando a configuração das relações, do poder e das práticas. Apresentei, ainda, a história da cesárea, de modo a ressaltar sua evolução histórica no contexto ocidental e, especificamente, no Brasil. Por fim, tracei um paralelo entre os procedimentos inerentes à rotina hospitalar no que concerne ao atendimento ao parto (cascatas de intervenções) e entre as informações e práticas inovadoras apontadas pelas evidências científicas. $^{2}$

No capítulo terceiro, fiz um paralelo entre a construção social de doença e da saúde e a construção social da parturição. Apresentei

2. A Medicina Baseada em Evidências (MBE) é um movimento internacional iniciado a partir da década de 1980. Parte do reconhecimento de que muitas práticas médicas não possuem respaldo de estudos sérios e científicos porque constatou que tais práticas médicas baseiam-se em tipos tendenciosos de pesquisas. (Diniz, Duarte, 2004). 
a parte da conjuntura atual por meio de uma releitura crítica de uma análise sociológica da Medicina, por meio de uma análise do discurso médico sobre o parto, o hospital como 'locus' de poder e a relação entre médico-paciente segundo dois modelos da sociologia: modelo conflituoso e o modelo consensual. Além disso, focalizei quais valores e idéias norteadoras colaboram na formação dos sentidos das experiências orgânicas dos sujeitos, visando compreender, desse modo, como se constitui a elaboração de uma realidade social e discursiva compartilhada coletivamente.

No quarto capítulo, abordei a temática da identidade e da ideologia, especialmente no que se refere à análise dos dados coletados. Por meio da aplicação do novo arcabouço da ADC, mais especialmente do tópico aprofundando a questão, realcei os itens relativos à análise propriamente dita - Análise do Discurso e Análise das Identidades - procurando compreender e explicar a constituição ideológica das identidades do médico/a e da mulher (grávida/parturiente), tanto na voz dos próprios médicos, como na voz das mulheres. Apontei as relevantes influências das práticas sociais localizadas ao longo da história da parturição na construção de tais identidades.

No quinto e último capítulo, focalizei os últimos três itens do arcabouço da ADC, quais sejam: definindo os principais obstáculos parte em que apresentei aspectos importantes que tornam a questão da assistência perinatal um tema pertinente na pós-modernidade, destacando suas facetas problemáticas; reconfigurando a questão - onde mencionei os caminhos que apontam para a mudança no paradigma intervencionista predominante nos dias atuais, destacando o discurso baseado nas evidências científicas, o papel e o lugar das enfermeiras obstétricas, e, ainda, acerca da função das acompanhantes de parto (doulas) na atualidade. Por fim, já nas considerações finais, utilizei o último item do arcabouço da $\mathrm{ADC}$ - refletindo sobre a análise - parte em que me dediquei a um exercício de reflexividade em torno da minha própria produção e contribuição sobre a temática em foco. Retomei, pois, as questões de pesquisa e os objetivos a fim de caminhar para um desfecho que me foi possível decorrente das escolhas realizadas ao longo da pesquisa. 
Optei por 'diluir' a análise de dados no decorrer dos capítulos da tese motivada por algumas razões. Em primeiro lugar, porque acredito que a pesquisa se torna mais clara ao ser apresentada de forma similar ao seu desenvolvimento: foi coletando e analisando os dados que pude dividir os capítulos nos temas apresentados para, assim, poder tecer a rede de argumentações. Em segundo lugar, a quantidade e a diversidade dos dados 'pediram' por uma diversidade de análise que contemplasse, pelo menos parte da amostra. Em muitos momentos, escolhi alguns dados para ilustrar as reflexões históricas e as práticas rotineiras na assistência ao parto. Por isso, nem todos os trechos citados foram analisados, em decorrência da quantidade e complexidade de dados. Optei por encaixar alguns trechos como ilustração a fim de legitimar o tópico em foco. Assim, apresentei os dados de maneira a serem pertinentes à minha reflexão - ora como material de análise mais profunda; ora como ilustração e composição argumentativa do que estava sendo explicitado. Gosto de dizer que minha coleta de dados pode ser comparada à do antropólogo que 'mergulhou' no contexto da pesquisa, passando, meses a fio, dormindo, acordando, trabalhando e comendo com os sujeitos pesquisados. Foi engravidando e parindo que escrevi a tese e foi trabalhando com grávidas diariamente, vivenciando minha maternidade profundamente, que pude coletar, analisar e apresentar os dados da pesquisa.

Espero que as contribuições propostas ao arcabouço da ADC sejam úteis para orientação das futuras pesquisas na área.

\section{Considerações finais}

A recontextualização do arcabouço analítico da Análise de Discurso Crítica pode ser considerada como mais uma parte do diálogo teórico e metodológico proporcionado pela perspectiva crítica da ADC. Como salientado por Chouliaraki e Fairclough (1999), o modelo de análise apresentado surgia, naquele momento, como um instrumento de caráter flexível. Os autores chamaram a atenção para as inúmeras possibilidades de aplicação do arcabouço, por meio da 
seleção e exclusão de determinados tópicos, da ênfase em outros, ou da inversão na ordem dos elementos.

A partir da prática das análises realizadas, no seio da ADC, desde 2000, observei que, muitas vezes, o analista repetia partes da análise já contempladas pelo arcabouço ao realizar as divisões padronizadas (introdução/teoria/metodologia/análise/conclusão) nos gêneros acadêmicos, como em artigos científicos, dissertação e tese. Proponho que o arcabouço analítico de Chouliaraki e Fairclough (1999), aqui ressignificado, seja aplicado de forma 'diluída' nas próprias seções desses gêneros mencionados.

Assim como arcabouço original, o modelo apresentado pode servir para orientar a produção textual no bojo da ADC, de modo que os itens elencados sejam utilizados em conformidade com as necessidades e os delineamentos específicos de cada pesquisa.

Recebido em: 02/09/2011

Aprovado em: 04/10/2011

ju.freitas.d@gmail.com

\section{Referências Bibliográficas}

ALTHUSSER, L. Ideologia e aparelhos ideológicos de estado. Lisboa, Presença, 1971.

BAUMAN, Z. Modernidade Líquida. Rio de Janeiro: Jorge Zahar, 2001.

BENVENISTE, E. Problemas de lingüística II. Campinas, São Paulo: Pontes, 1989.

CHOULIARAKI, L.; FAIRCLOUGH, N. Discourse in late modernity: rethinking Critical Discourse Analisy. Edinburgh University Press. 1999.

DAMASCENO, R. O Eminente Discurso da Queda Iminente. Dissertação de mestrado. Programa de Pós Graduação em Linguística. Universidade de Brasília, 2005.

DIAS, J. F. O renascimento do parto: discurso e identidade. Tese de doutorado. Programa de Pós-Graduação em Linguística. Universidade de Brasília, 2007. 
FAIRCLOUGH, N. Discourse and Social Change. Cambridge, Polity press, 1992. FAIRCLOUGH, N. Discurso e mudança social. Coordenadora de tradução: Izabel Magalhães. Brasília: Universidade de Brasília, 2001.

FAIRCLOUGH, N. Analysing Discourse - textual analisys for social research. Routledge: London, 2003.

GIDDENS, A. Modernity and self-identity: self and society in late modern age. Cambridge, Polity Press, 1991.

GIDDENS, A. Modernidade e Identidade. Rio de Janeiro: Jorge Zahar, 2002. HALLIDAY, M. Introduction to functional grammar. Londres: Edward Arnold, 1985.

HALL, S. A identidade cultural na pós-modernidade. $4^{\mathrm{a}}$ edição. Rio de Janeiro RJ, DP \& A, 1992.

IÑIGUEZ, L. Manual de Análise do Discurso em Ciências Sociais. Rio de Janeiro: Vozes, 2004.

MAGALHÃES, I. Eu e Tu: a constituição do sujeito no discurso médico. Brasilia: Thesaurus, 2000.

RAJAGOPALAN, K. Teorizando a resistência. In: SILVA, D. E. G.; VIEIRA, J. A. (Orgs.) Análise do discurso: percursos teóricos e metodológicos. Brasília: UnB. Oficina Editorial do Instituto de Letras: Ed. Plano, 2002, p. 203-220.

RAMALHO, V.; RESENDE, V. M. Análise de discurso (para a) crítica: o texto como material de pesquisa. Campinas: Pontes, 2011.

RESENDE, V. M.; RAMALHO, V. Análise de Discurso Crítica. São Paulo: Contexto, 2006.

SILVA, T. T.; HALL, S. \& WOODWARD, H. Identidade e diferença. Rio de Janeiro: Vozes, 2000.

SILVA, D. E. G. et al. (Orgs.) Discurso em questão: representação, gênero, identidade, discriminação. Goiânia: Cânone, 2009.

SILVA, D. E. G.; VIEIRA, J. A. (Orgs) Análise do discurso - percursos teóricos e metodológicos. Brasília: Plano, 2002.

THOMPSON, J. B. Ideologia e cultura moderna. Petrópolis, Vozes, 1995.

VIEIRA, J. A.; SILVA, D. E. G. (Orgs.). Práticas de Análise do Discurso. Brasília: Plano; Oficina Editorial do Instituto de Letras, 2003, p. 161-171. 